\title{
Esperando o futuro: a maternidade na adolescência
}

\section{| 1 Silvia Alexim Nunes |}

Resumo: Este artigo é parte de um projeto que pretende avaliar o lugar da maternidade na constituição da subjetividade de um grupo de adolescentes. Parte da hipótese de que a gravidez na adolescência só se tornou um problema político e social dentro de uma biopolítica voltada para a produção e reprodução do corpo social que pressupõe a maternidade como um projeto racional. Nesse contexto, a gravidez na adolescência tornase um problema de saúde pública, e os discursos sobre o tema adotam um tom homogeneizante e estigmatizante, acentuando seus aspectos negativos. A pesquisa, realizada com adolescentes de camadas populares entre 16 e 18 anos de idade, permite questionar esses discursos. Apontou a maternidade como um acontecimento fundamental para a constituição da subjetividade dessas jovens, possibilitando a construção de ideais e a articulação de um projeto de futuro.

> Palavras-chave: adolescência, gravidez, maternidade, biopolítica, formas de subjetivação.
${ }^{1}$ Médica, psicanalista; doutora em Saúde Coletiva (IMS-UERJ); pesquisadora do grupo Epos, genealogia, subjetivações e violências (IMS-UERJ); membro do Espaço Brasileiro de Estudos Psicanalíticos Endereço eletrônico: silviaalexim@uol.com.br

Recebido em: 10/12/2009 Aprovado em: 24/08/2010 
Nas últimas décadas, pudemos observar um interesse crescente pelas questôes ligadas à juventude, seja em relação às demandas e necessidades dos jovens ou em relação aos problemas por eles colocados. ${ }^{1}$ Dentre os temas levantados com mais frequência, a gravidez na adolescência tem papel de destaque. Considerada um problema social, ela geralmente é abordada num tom relativamente alarmista e como um mal a ser evitado.

Dois pontos me parecem fundamentais em relação ao tratamento dado à gravidez na adolescência no âmbito tanto dos discursos oficiais quanto dos veiculados pela mídia, especializada ou não. $\mathrm{O}$ primeiro é que tais discursos abordam o problema a partir de uma perspectiva universalista, homogeneizando as diferenças relativas às faixas etárias e às inserçôes sociais. $\mathrm{O}$ segundo é que o tratam como um fenômeno anistórico, isto é, que independe das condições históricas, culturais e sociais que o configuraram como um problema.

A hipótese que norteia este trabalho é que a gravidez na adolescência só se tornou um problema a partir do momento em que, na atualidade, entrou na contramão de um projeto político de gestão da produção e reprodução do corpo social que pressupõe a maternidade como um projeto racional. Nessa perspectiva, a transformação da maternidade na adolescência em um problema social é parte de uma estratégia biopolítica voltada para a regulação e produção da vida. Nesse contexto, tornou-se uma questão de saúde pública, principalmente a partir da década de 1980, quando os estudos sobre o tema tomaram impulso. Surge então o pressuposto de que a gravidez antes dos 20 anos acarretaria riscos sociais e problemas tanto para a mãe quanto para a prole (BRUNO et al., 2002).

É importante lembrar que, décadas atrás, a maternidade antes dos 20 anos não constituía assunto alarmante, sendo, ao contrário, até bem-vinda quando dentro de um projeto matrimonial, pois as moças com mais de 20 anos, sem perspectivas de casamento, eram vistas como "encalhadas", e aos 25, consideradas "solteironas" (BASSANEZI, 1997). Historicamente, o fato de as mulheres engravidarem no início de sua vida reprodutiva foi durante muitos séculos lugar-comum, pois ser mãe era considerado um destino feminino ideal e quase inevitável (PERROT, 2007). 
Este trabalho faz parte de uma pesquisa através da qual procurei avaliar o lugar da maternidade na constituição da subjetividade de um grupo de adolescentes de camadas populares. Jovens moradoras de comunidades situadas em bairros da Zona Norte do Rio de Janeiro e suas vizinhanças, com renda familiar até três salários mínimos. Embora tenham inserção social e condições econômicas bastante semelhantes, elas têm histórias muito singulares. São jovens de origens diferentes, cinco vindas do Nordeste e cinco nascidas aqui. A organização familiar é variada: duas famílias nucleares, cinco monoparentais, cuja principal responsável pelos filhos é a mãe, e três ampliadas, seja a partir de separações e novos rearranjos, ou devido à inclusão no convívio doméstico de parentes como avós, tios e primos.

Todas frequentam ou frequentaram a rede pública de ensino. Metade delas continua estudando, duas terminando o ensino fundamental e três cursam o ensino médio. Duas outras abandonaram a escola antes mesmo de engravidar, sem cursar o ensino médio, e três interromperam o ensino médio a partir da gravidez. Dentre estas, as duas jovens que estavam com bebês recém-nascidos alegaram um afastamento temporário com planos de retomar os estudos em alguns meses. Sete jovens já vivem com o pai da criança, duas das quais junto à sua família de origem e uma junto à família de origem do marido. As que permanecem morando com a própria família de origem mantêm um relacionamento com o parceiro, uma pretende morar junto assim que possível e uma outra não tem planos imediatos de deixar a casa da mãe. Sete dessas jovens exercem algum tipo de atividade remunerada para ajudar em casa.

A pesquisa foi realizada em um ambulatório público de atendimento a adolescentes, na Zona Norte do Rio de Janeiro, ${ }^{2}$ e conduzida dentro dos padrões éticos exigidos pela Comissão Nacional de Ética em Pesquisa/Conselho Nacional de Saúde/Ministério da Saúde.

Foram realizadas dez entrevistas com adolescentes grávidas ou mães, entre 16 e 18 anos de idade. A perspectiva metodológica privilegiou o discurso das entrevistadas como via de acesso às vivências emocionais dessas adolescentes, procurando avaliar a importância da gravidez e da maternidade para sua subjetividade, suas motivações, desejos e fantasias. As jovens foram convidadas 
a participar da pesquisa através de contato pessoal feito no próprio ambulatório, ocasião em que era agendada a entrevista. Quase todas aceitaram de bom grado o convite e apenas uma das abordadas se recusou a participar. As entrevistas foram individuais, realizadas no próprio ambulatório em sala privativa, sem duração previamente determinada, e registradas em gravação. $O$ roteiro privilegiou a história pessoal, vida familiar e escolar, educação e experiência sexual, relações amorosas, história da gravidez e projetos de vida.

\section{Feminilidade e formas de subjetivação}

Em trabalho anterior (NUNES, 2000), procurei mostrar como na modernidade a maternidade se tornou o centro da vida feminina, sendo considerada um ideal e identificada com a essência e a natureza femininas. Nesse processo, foi tratada como destino politicamente desejável para as mulheres, em um contexto no qual outras possibilidades subjetivas foram classificadas como "desviantes" e "antinaturais". ${ }^{3}$

A partir de uma preocupação política com a produção da vida e da qualidade da população, no momento em que a população começa a ser pensada como fonte de riqueza das naçôes, a mulher e a maternidade tornaram-se objetos privilegiados de intervenção e controle. O que estava em pauta era a constituição de uma biopolítica concebida como a condição de possibilidade do manejo das fontes da vida para a produção da riqueza material e para a regulação dos laços sociais (FOUCAULT, 1977). Nesse contexto, a sexualidade transformou-se em objeto privilegiado de medicalização, pois seria pela regulação da reprodução individual e coletiva que a produção de um corpo saudável e disciplinado estaria garantida (FOUCAULT, 1994).

É no bojo desse processo que se constituiu a família nuclear burguesa. Modelo familiar que foi concebido, ao longo dos séculos XVIII e XIX, como um espaço privilegiado para a constituição do biopoder, por ser a matriz da produção e reprodução dos indivíduos (BIRMAN, 2001). Antes relegada a uma espécie de limbo, a mulher ganhou então não só um novo valor dentro da ordem familiar, como também o poder de governabilidade do espaço doméstico, tornando-se a responsável pela produção de uma prole saudável (DONZELOT, 1980). Pensada como peça-chave da estratégia de produção da vida e da saúde das crianças, a mãe tornou-se um dos pilares do biopoder, constituindo-se no agente familiar de um projeto mais global de higiene social. 
Transformar a mulher em mãe foi, no entanto, tarefa que exigiu um processo maciço de medicalização do corpo feminino. Os discursos médicos passaram a descrevê-lo como um corpo saturado de sexualidade e portador de um excesso ameaçador que deveria ser regulado minuciosamente. A sexualidade feminina foi então concebida como dotada de um potencial degenerador do corpo e da alma capaz de desvirtuar o caráter da mulher (NUNES, 1991). Para minimizar os riscos colocados por essa sexualidade ameaçadora, instituiu-se um sem-número de regras de higiene, inaugurando-se uma estratégia de controle minucioso da vida e da sexualidade feminina. Parto, aleitamento, ciclos hormonais, condutas sexuais, cuidados com os filhos, vestimentas, hábitos alimentares, atividades sociais, tudo deveria ser pensado e medido de acordo com prescrições médicas que visavam a conter os excessos e ardores femininos, adestrando as mulheres para a maternidade. A mulher burguesa precisava, antes de mais nada, adestrar seu erotismo atrelando seu desejo exclusivamente à relação com o filho e o marido (NUNES, 2000).

As mudanças na cultura e a ampliação do horizonte feminino para além da esfera doméstica abriram novas possibilidades subjetivas e expectativas de vida para as mulheres. A entrada das mulheres das camadas média e alta no mercado de trabalho e o advento da pílula anticoncepcional permitiram de forma mais eficaz que elas pudessem decidir se e quando querem ter filhos. Isso implicou uma alteração nos padrões de fecundidade da população feminina (NÉRI, 2007). Observa-se nas mulheres dos setores economicamente favorecidos o adiamento do projeto de maternidade e a queda no padrão de fecundidade. Essas mulheres passaram a ter menos filhos, quando não decidem não tê-los, procurando postergar a maternidade até o último minuto da vida reprodutiva, privilegiando na juventude a construção de um projeto profissional. No entanto, isso não significou um arrefecimento da medicalização do corpo feminino, e muito menos uma transformação no projeto biopolítico de gestão populacional. Corrêa (2001) aponta uma ampliação desse processo, a partir do desenvolvimento de novas formas de controle da fecundidade e da concepção, de pesquisas genéticas com fins preditivos e intervencionistas e de técnicas de reprodução assistida. Isso tornou possível um controle mais eficaz sobre os processos reprodutivos.

Nesse contexto, o planejamento dos filhos, quantos e quando, tornou a reprodução biológica um fenômeno altamente investido racional e tecnologicamente. A maternidade, identificada na modernidade como uma 
condição natural feminina, ideal a ser alcançado, e forma privilegiada de subjetivação, já não se sustenta enquanto tal. A opção por não ter filhos tornou-se uma realidade. Além disso, como ressalta Corrêa, a norma da maternidade mudou de contornos, assumindo traços específicos: o "normal" numa mulher hoje é um estado de não concepção medicalizado até o momento considerado adequado, o que resultou, entre outras coisas, num aumento da idade de procriar. ${ }^{4}$ Ter filhos deve ser agora uma decisão deliberada, na qual pesem fatores como a colocação no mercado de trabalho, a estabilidade do casal, o desejo de concluir os estudos, a preocupação com os meios disponíveis para proporcionar uma vida saudável e uma boa educação (CORRÊA, 2001). O que podemos perceber, portanto, é a intensificação de uma biopolítica de gestão da reprodução do corpo social.

Ora, a maternidade na adolescência situa-se num campo completamente oposto ao que se considera na atualidade um projeto racional de reprodução. $\mathrm{Na}$ contramão dessa medicalização, as adolescentes engravidam "fora de hora". A gravidez na adolescência aparece então como um problema de saúde pública (DADOORIAN, 2000) e ganha lugar de destaque nas políticas voltadas para o controle da reprodução individual e coletiva, ou seja, no projeto biopolítico de gestão populacional.

Até meados do século XX, os projetos médicos voltados para as jovens tinham como meta privilegiada disciplinar sua sexualidade, adestrando-as desde cedo para a vida doméstica (NUNES, 1988). Assim, a maternidade, quando dentro do casamento, tornou-se a fonte privilegiada de sublimação e subjetivação para as adolescentes. $\mathrm{Na}$ atualidade, observa-se uma mudança de alvo, e a maternidade na adolescência é tratada como precoce e indesejável. No momento em que ser mãe passou a ser um projeto tardio e opcional, mesmo que dentro de uma relação conjugal, será preciso adestrar o erotismo da jovem adequando-o aos novos ideais e expectativas sociais, encontrar novos destinos para a sexualidade feminina juvenil percebida como impulsiva e difícil de governar. Percepção resultante da superposição da representação moderna da sexualidade feminina como potencialmente "degenerável e perigosa" com a representação da sexualidade adolescente também concebida na modernidade como "potencialmente desreguladora" e um "risco" a ser controlado. 


\section{Adolescência e sexualidade}

Nas sociedades ocidentais, a noção de adolescência é datada. A formulação da existência de uma fase intermediária ou de passagem entre a infância e a idade adulta só se deu a partir do século XVIII, cristalizando-se no século XIX. Até o século XVIII, a adolescência não era destacada como uma fase específica da vida, sendo confundida com a infância. A longa duração da infância, que no senso comum podia chegar até 24 anos, provinha da indiferença que se sentia pelos fenômenos biológicos. Não se limitava a infância pela puberdade. A ideia de infância estava ligada à ideia de dependência. Só se saía da infância ao se tornar independente. Não se concebia a adolescência como uma fase específica da vida, uma passagem entre a infância e a idade adulta (ARIÈS, 1978).

Foi a associação do início da juventude com as transformações da puberdade que desencadeou o processo de constituição de uma idade da vida diferenciada e que hoje entendemos como adolescência. Essa formulação da puberdade como o marco que anuncia o fim da infância e o início da juventude começou a ser desenhada no século XVIII. Rousseau foi seu grande artífice. Destacou o período entre a primeira comunhão e o bacharelado para os meninos, e o casamento para as moças, como crucial para os indivíduos, porém pleno de promessas e riscos. É o momento do nascimento para o sexo que é considerado um "momento crítico" (ROUSSEAU, 1762-1992).

Essa noção de momento crítico vai ser retomada ao longo do século XIX, notadamente pelos médicos, que escreveram dezenas de teses sobre a puberdade dos meninos e das meninas e os remédios a ser ministrados (VAN USSEL, 1980; FREIRE COSTA, 1979). O que inquietava esses médicos era a transformação sexual dos jovens. Assim, no momento em que a juventude começa a ser demarcada como um período que se inicia com as transformaçôes da puberdade, a sexualidade adolescente vai ser problematizada como um risco a ser controlado (PERROT, 1991).

Essa preocupação não estava isolada de uma preocupação mais geral com a questão da sexualidade humana e seus desvios que marcou o século XIX. Foi nesse momento que uma sexologia nascente produziu um discurso científico sobre o sexo, que determinava o que era lícito ou ilícito em termos sexuais. Tarefa 
que era até então assumida pelo discurso religioso. Nesse novo contexto, o sexo do jovem, assim como o da mulher, passou a ser objeto privilegiado de uma vontade de saber sobre o sexo que marcou as sociedades ocidentais modernas (FOUCAULT, 1977). Preocupação que tinha como alvo, entre outros, o controle dos ardores juvenis e seus desvios, percebidos como ameaça à ordem social e à produção de uma prole saudável. Foi, portanto, no bojo da constituição do biopoder que a criança e o jovem se tornaram alvos primordiais de intervenção e controle. A biopolítica que pressupõe a vida como riqueza, bem máximo a ser produzido, preservado e reproduzido, transformou o sexo do adolescente em um problema médico e moral, que deveria ser disciplinado, seja no âmbito familiar, seja nos colégios e internatos (FOUCAULT, 1994).

Esse processo visava tanto a preservação e otimização da capacidade produtiva e reprodutiva dos futuros pais e mães, como também à própria formação dos jovens, que deveria implicar um aperfeiçoamento e adestramento de seu corpo, suas paixões e seus excessos. Os discursos e as práticas voltadas para o controle do onanismo, considerado fonte de degeneração física e moral, confirmam essa preocupação. $\mathrm{O}$ jovem era ensinado a temer seu corpo e seus desejos, e toda sua vida passou a ser vigiada com o intuito de evitar uma entrega a prazeres perigosos e proibidos. $\mathrm{O}$ controle da privacidade e das oportunidades do exercício de uma sexualidade desviante encontrava-se no cerne das tarefas educativas e médicas (FOUCAULT, 1977).

O sexo dos jovens precisava ser vigiado constantemente. Masturbação, homossexualidade latente, gravidez indesejada, ${ }^{5}$ possíveis perversidades atormentam os médicos, observadores privilegiados que eram desses corpos. A ternura que envolve a imagem da criança vai aos poucos sendo tingida de desconfiança e distanciamento em relação ao adolescente. Desenha-se um quadro no qual o desejo sexual do jovem poderia ser a porta de entrada para a violência. Desliza-se imperceptivelmente para o tema do adolescente criminoso, antissocial, visto como um vagabundo nato (PERROT, 1991).

A percepção da sexualidade adolescente como excessiva, uma irrupção incontrolável, desintegradora de si e do mundo externo, abriu as portas para uma concepção da adolescência como um risco a ser controlado. Foi essa representação da sexualidade, na qual a puberdade aparece como um marco ameaçador, que definiu de forma indelével os discursos médicos e psicológicos 
sobre a adolescência. Essa representação encontra-se ainda hoje no centro das estratégias de regulação do corpo e da vida juvenil.

Tal diretriz caucionou um processo de medicalização que, nas últimas décadas do século XX, elegeu a adolescência como um de seus objetos privilegiados. Nesse processo, colocou-se em primeiro plano a necessidade de uma regulação e disciplinarização da sexualidade adolescente, o que se deu no bojo da constituição de uma medicina voltada para esse período da vida, até então absorvido ou pela pediatria ou pela clínica de adultos.

\section{A constituição de uma medicina da adolescência}

Segundo Coates (1999), a preocupação médica com a adolescência no Brasil surgiu de forma incipiente na década de 1950, com esforços isolados e voltados para o problema dos menores em perigo social, e temas como abandono e delinquência juvenil começaram a ser debatidos no âmbito da formação médica. No Rio Grande do Sul foi inaugurado, em 1965, o primeiro serviço médico de atendimento a adolescentes, uma clínica de internação psiquiátrica. Em Porto Alegre, em 1969, foi criado o Programa de Atenção à Saúde do Educando, que serviu de modelo para escolas públicas e privadas.

Foi contudo na década de 1970 que uma medicina voltada especificamente para a adolescência deu seus passos iniciais, com a criação dos primeiros serviços de Atenção à Saúde Integral do Adolescente, em São Paulo e no Rio de Janeiro. Seus programas visavam a respeitar características e peculiaridades dessa fase da vida, tendo por finalidade promoção, proteção e recuperação da saúde do adolescente de forma global - orgânica e psicossocial. Esses serviços de assistência ao adolescente se expandiram e multiplicaram por todo país, dando origem, em 1989, à Associação Brasileira de Adolescência (ASBRA), de caráter multidisciplinar, cuja finalidade era identificar as necessidades e proporcionar atendimento global aos adolescentes brasileiros. No início de 1998, com a criação da Secretaria de Políticas de Saúde, o Serviço de Assistência à Saúde do Adolescente passou a ser Área Técnica da Saúde na Adolescência, subordinada ao Departamento de Gestão de Políticas Estratégicas (COATES, 1999). Desse modo, o surgimento de uma medicina dirigida especificamente para a adolescência se deu no cerne de todo um projeto político e social voltado para essa camada da população. 
É interessante observar que a noção de assistência integral que marca o projeto de cuidados com a saúde na adolescência pressupõe uma abordagem psicossocial do jovem. Em outras palavras, uma abordagem que não se esgota na doença, voltando-se principalmente para as dimensões sociais e emocionais da experiência juvenil. Chama a atenção o fato de os médicos desses serviços apontarem que não existem doenças específicas da adolescência que demandem cuidado especializado. Aliás, consideram essa fase da vida como a mais saudável, isto é, uma fase na qual se adoece pouco (COSTA, 2007).

Isso demonstra que o fator determinante de um crescente processo de medicalização da adolescência, com o aparecimento de uma nova especialidade médica, a hebiatria, é na verdade a associação da adolescência com a ideia de risco social. De um lado, a adolescência é merecedora de cuidados e atenção por serem os jovens considerados mais vulneráveis aos fatores de risco presentes no meio social; de outro, o adolescente é percebido como um risco para a sociedade por assumir comportamentos "desviantes". No bojo da constituição de um projeto de atenção à juventude, os discursos médicos vão abordar, para além de problemas clínicos, temas diversos como gravidez precoce, tráfico de drogas e violência urbana.

\section{Gravidez na adolescência e risco}

No Brasil, o debate sobre a gravidez na adolescência teve início no âmbito da saúde pública. Nas últimas décadas do século passado observou-se que, apesar do declínio das taxas de fecundidade em geral, a proporção de partos entre adolescentes cresceu em comparação com o total de partos realizados no país. A Pesquisa Nacional de Demografia e Saúde de 1996 revelou que nos dez anos que a antecederam houve diminuição da fecundidade em torno de $30 \%$ em todas as faixas etárias, com exceção da adolescente. De acordo com o Ministério da Saúde, a gravidez na faixa de 15 a 19 anos cresceu 26\% entre os anos 1970 e 1991, contrariando a tendência geral de diminuição das taxas de fecundidade (BRUNO et al., 2002), panorama que se manteve inalterado nos últimos anos. Segundo dados do SUS relativos a 2000, dos 2,5 milhóes de partos realizados nos hospitais públicos do país, 689 mil eram mães adolescentes com até 19 anos de idade (DADOORIAN, 2000). 
Diante desse quadro, a gravidez na adolescência foi considerada um problema social, e os discursos sobre o tema, tanto no âmbito das políticas públicas quanto da mídia, passaram a considerá-la um mal a ser evitado. A gravidez na adolescência é, de maneira geral, associada a problemas sociais complexos como incremento da pobreza, delinquência, aumento da criminalidade, violência, uso e tráfico de drogas. Uma associação que de forma sutil tinge a maternidade na adolescência com as cores da criminalização e da patologização.

A gravidez na adolescência é considerada um problema mundial. Não por acaso, instituiu-se recentemente o dia 26 de setembro como "Dia Mundial da Prevenção da Gravidez na Adolescência”. No entanto, embora os programas sociais e políticas de saúde que pretendem combater o fenômeno partam de uma perspectiva homogeneizante, os dados demográficos apontam que o grande contingente de jovens mães está nos países ditos em desenvolvimento ou nas camadas populares dos países desenvolvidos (SOBRINHO et al., 2002). São essas adolescentes os alvos preferenciais das políticas voltadas para a prevenção do problema.

$\mathrm{O}$ que parece se evidenciar é que o combate à maternidade na adolescência é parte de um projeto de controle da natalidade nas populações economicamente desfavorecidas, cuja fertilidade é percebida como fonte de risco, devendo ser limitada para prevenir superpopulação (BAUMAN, 2005), pobreza, marginalidade e criminalidade. Como assinala Castro, de forma mais ou menos explicitada concebe-se a criança pobre como um marginal em potencial, procurando-se, consequentemente, erradicar o mal pela raiz (CASTRO, 1980). O que podemos observar, portanto, é a intensificação de uma biopolítica de gestão da reprodução do corpo social que precisa se tornar cada vez mais abrangente e seletiva.

Em toda essa produção discursiva e nos projetos de prevenção visando à gravidez na adolescência, dois aspectos são sempre enfatizados e merecem ser problematizados, pois estão intimamente imbricados. O primeiro é que de uma maneira geral relaciona-se a gravidez na adolescência às transformações na esfera da sexualidade que tiveram lugar a partir da década de 1960. Argumenta-se que as mudanças na cultura, que levaram a uma maior liberação do sexo, ocorreram sem que simultaneamente fossem transmitidas informações sobre os métodos contraceptivos de modo a facilitar o acesso a eles. Assim, consideram-se como fatores predisponentes a desinformação juvenil e a dificuldade de acesso aos 
métodos anticoncepcionais. O segundo aspecto é que, dentre os efeitos danosos atribuídos à gravidez na adolescência, destaca-se o pressuposto de que ela levaria ao abandono da escola, com consequente prejuízo para a formação profissional da jovem, que terá então menores chances no mercado de trabalho.

Pesquisas recentes têm questionado esses pressupostos. É frequente a constatação de que as jovens engravidam apesar de bem informadas e terem acesso aos métodos contraceptivos (DADOORIAN, 2000; BRANDÃO; HEILBORN, 2006). Além disso, em relação ao abandono da escola, os estudos apontam que na maioria das vezes em que isso ocorre, geralmente nas camadas economicamente desfavorecidas, a jovem já saiu da escola ao ficar grávida. Esse dado está de acordo com outro revelado em recente pesquisa, que apontou o desinteresse como o principal motivo de evasão escolar dos jovens entre 15 e 17 anos (NÉRI, 2009).

Heiborn sugere que uma postura preventiva frente à gravidez é mais evidente nas jovens com maiores possibilidades de construir projetos a médio prazo que seriam prejudicados pela gravidez, ou seja, jovens de estratos econômicos e sociais mais favorecidos. Inversamente, a ausência de qualquer perspectiva escolar ou profissional, produto de uma escolaridade irregular, faz com que as jovens das camadas populares não considerem uma eventual gravidez como perturbação maior, daí não se preocuparem em tentar evitá-la (HEILBORN, 2006). Isso demonstra que os projetos educacionais e profissionalizantes voltados para essa população são pouco convidativos e incapazes de apresentar alternativas atraentes para descartar a opção pela maternidade nessa época da vida.

Portanto, embora a desinformação e a dificuldade de acesso aos métodos anticoncepcionais possam colaborar para a dificuldade de introjeção e do exercício das normas contraceptivas, na maior parte das vezes não parecem ser essas as principais causas dos impasses com que as políticas de controle da natalidade entre as jovens se defrontam. A valorização da maternidade por essas jovens e as precárias possibilidades de articular alternativas de vida suficientemente atraentes para justificar seu adiamento têm aqui papel de destaque.

Em nossa pesquisa, as dez jovens entrevistadas afirmaram ter conhecimento e acesso a métodos contraceptivos. Além disso, seis delas admitiram não ter se prevenido porque desejavam engravidar. Das outras quatro, duas alegaram estar fazendo algum tipo de prevenção que falhou, e as demais, ter acontecido "sem querer", no calor de uma relação sexual imprevista. Mas mesmo as jovens que 
declararam preferir que o desejo de ser mãe só se realizasse um pouco mais tarde reconheceram que, passado o "susto", ficaram felizes com a maternidade. Logo, pudemos observar situaçóes em que a gravidez foi programada e outras em que, apesar de não ter sido programada, nem por isso foi indesejada, fazendo parte de um projeto de vida previamente estabelecido que pressupóe a maternidade e a constituição de um núcleo familiar. Todas as jovens declararam que sempre quiseram ter filhos, sendo a maternidade um sonho acalentado desde muito cedo e ao qual atribuem grande valor.

Nesse mesmo sentido, Fachel e Leal apontam que a gravidez na adolescência nas classes populares não é necessariamente percebida como problema, em função da enorme valorização cultural da gravidez e da maternidade por essa população. Tal valorização é elemento fundamental dentro de uma rede de arranjos domésticos de consanguinidades, afinidades, papéis e prestígio social (FACHEL; LEAL, 1999). A mãe é considerada a força moral e principal referência, capaz de influenciar nos comportamentos e na administração dos conflitos.

As redefinições do papel e do lugar social feminino possibilitaram que as mulheres passassem a ter menos filhos, ou mesmo decidissem simplesmente não tê-los, procurando postergar a maternidade até o último minuto da vida reprodutiva, privilegiando na juventude a construção de um projeto profissional, que implica um prolongamento dos estudos e a obtenção de reconhecimento e estabilidade profissionais. Contudo, sabemos que esse quadro auspicioso de oportunidades de vida e futuro promissor, de certa forma válido para as jovens das camadas economicamente favorecidas, não se apresenta da mesma forma para aquelas das camadas economicamente desfavorecidas. Essas se confrontam com muito mais dificuldades, sem fácil acesso às mesmas oportunidades. Muitas vezes, premidas pela necessidade, frequentam pouco a escola e precisam trabalhar para colaborar com a renda familiar. Lidar com uma realidade social adversa se torna tarefa cotidiana, que marca a constituição de sua subjetividade e de suas formas de vida.

No entanto, as perspectivas abertas para as adolescentes das camadas alta e média forjam o imaginário social sobre um suposto destino alvissareiro reservado à juventude, que tende a ser universalizado como um novo ideal. Espera-se que as jovens dos diferentes estratos sociais terminem seus estudos e adquiram uma estabilidade profissional, como se esse ideal fosse acessível a todas. 
Em nossa sociedade, a adolescência é uma fase crucial no processo de construção da subjetividade. É preciso lidar tanto com as incertezas relativas às transformações do corpo e do espírito, quanto com as dificuldades de crescer no quadro da família e da sociedade. Dificuldades que têm papel fundamental nas escolhas decisivas que possibilitam a inserção na vida social enquanto adultos. Calligaris aponta que, em nossa cultura, a criança, à medida que cresce, aprende, entre outras coisas, que existem dois campos nos quais precisa se destacar para alcançar a felicidade e o reconhecimento social: as relações amorosas, sexuais e a potência no campo produtivo (CALLIGARIS, 2000).

Ora, no que diz respeito ao jovem brasileiro das camadas populares, a probabilidade de se destacar no campo produtivo é bastante limitada. Como assinala Birman, a ostensiva desigualdade na distribuição do gozo que caracteriza a sociedade brasileira e a ausência de um Estado que regule minimamente essa repartição lançam ao mais completo abandono parcelas significativas da população (BIRMAN, 2006). O efeito disso sobre crianças e adolescentes pode ser devastador. Felicidade e reconhecimento social tornamse ideais muito distantes.

Confrontadas com esta realidade, as jovens das camadas populares vão precisar encontrar destinos para suas potencialidades, sua feminilidade, seu erotismo, suas angústias e inseguranças. Diante da precária oferta de condições que lhes permitam ampliar seus projetos de vida, o desejo de tornar-se mãe ganha lugar fundamental no processo de subjetivação de muitas dessas adolescentes. Desejo que se manifesta em duas dimensões. Em sua dimensão coletiva, aparece como resistência às políticas de controle e adestramento de sua capacidade reprodutiva. Em sua dimensão singular, como forma de subjetivação privilegiada dentro de um quadro de restritas oportunidades sociais.

Em sua vertente coletiva, a dimensão de resistência fica evidenciada, por exemplo, pela frequente não adesão aos métodos contraceptivos, dado apontado por diferentes pesquisas (BRANDÃO; HEILBORN, 2006; DADOORIAN, 2000). Na contramão de uma biopolítica que, através de novas formas de adestramento e disciplinarização da sexualidade juvenil, pretende regular sua fertilidade, essas jovens resistem a tais estratégias de controle e emergem das 
malhas do biopoder como um novo personagem social. A adolescente grávida se torna, então, um personagem "desviante". Mas, ao transgredir as normas às quais deveria se adequar, exibe sua potência e sua capacidade de se lançar no futuro e, dessa forma, perseverar na existência.

Em sua vertente singular, o desejo de tornar-se mãe constitui uma forma de subjetivação privilegiada dentro de um quadro de restritas oportunidades sociais. As adolescentes entrevistadas foram unânimes em declarar que sempre acalentaram o sonho de ser mãe e se disseram felizes com essa possibilidade. Para elas, a maternidade propiciou a articulação de um projeto de futuro, que se anunciava até então obscuro e sem muitos atrativos, dadas as dificuldades que encontravam em seu cotidiano para formular projetos alternativos. Lidiane, por exemplo, tem 17 anos e queria ser escritora, mas "os livros são caros e na biblioteca do colégio só pode tirar um livro a cada dois meses, é pouco”. Perto de onde mora não existem bibliotecas. Taíssa, aos 16, é superesportiva, queria ser ginasta. Frequentou um projeto em sua comunidade, "mas o projeto acabou e tive que parar". Muito dedicada aos estudos, Mirela, de 20 anos, queria ser médica, "mas acho que não consigo passar no vestibular".

Esse quadro de poucas alternativas pode ter consequências psíquicas bastante negativas. A impossibilidade de sustentar uma imagem narcísica positiva e de constituição de ideais, fundamentais para a articulação de qualquer projeto de futuro, é um risco com o qual essas jovens estão se confrontando. A falência narcísica e a ausência de ideais podem se tornar fontes poderosas de desamparo e desestruturação psíquica. A maternidade pode se apresentar, então, como forma de subjetivação possível e desejável, essencial para a necessária sustentação do narcisismo dessas adolescentes, assim como para a construção de ideais e projetos de vida. Torna-se, assim, um ideal muito bem-vindo. Ideal que com frequência se revela o único capaz de assegurar a essas jovens um lugar ao sol valorizado por elas e por seus pares e, consequentemente, a satisfação de sua autoestima e da necessidade de reconhecimento pelo outro.

Os discursos médicos e psicológicos, ao abordarem a maternidade na adolescência a partir de uma perspectiva generalizante, tendem a desconsiderar os aspectos positivos e singulares dessa experiência e acentuar seus possíveis efeitos nocivos. Gostaria de problematizar essa perspectiva. 


\section{No caso dela não foi problema, foi solução}

Formulados no âmbito da saúde pública, os discursos médicos discorrem sobre os resultados indesejáveis de uma fecundidade precoce, valorizando as consequências negativas para a saúde da mãe e da criança. $\mathrm{O}$ aborto espontâneo, a prematuridade e mesmo a morte do bebê são os maiores riscos apontados (BRUNO et al., 2000). Associados aos discursos médicos, os discursos psicológicos acrescentaram a esse inventário de perigos os riscos psicossociais em função da imaturidade psicológica da jovem para criar uma criança, que ficaria mais propensa a contrair doenças ou sofrer acidentes (FIGUEIREDO, 2000). Além disso, os discursos psiquiátricos apontam que a ocorrência da maternidade durante a adolescência pode ter graves consequências psíquicas para a mãe. Ansiedade, depressão, ideação suicida são alguns dos transtornos relatados (FREITAS, 2007).

No âmbito dos estudos psiquiátricos, é crescente o número de pesquisas que procuram avaliar a incidência de depressão pré e pós-parto em adolescentes. A ocorrência de depressão em torno da gravidez e do parto é hoje um problema que médicos e psiquiatras consideram cada vez mais frequente. No entanto, é interessante observar que em diferentes estudos os dados não são conclusivos quanto a uma maior incidência desses quadros em adolescentes, com relação às demais faixas etárias. $\mathrm{O}$ que fica mais evidenciado é que a ocorrência desses quadros depressivos em jovens mães está geralmente associada a condições sociais extremamente precárias, em que pobreza e violências diversas fazem parte da história e do cotidiano dessas adolescentes (FREITAS; BOTEGA, 2002). Paralelamente, alguns estudos que pretendem avaliar a incidência dessas formas de depressão em mulheres de diferentes faixas etárias destacam a não-aceitação da gravidez, para todas as camadas sociais, e as precárias condições socioeconômicas como os fatores que mais influenciam o desencadeamento de um quadro depressivo, sem ênfase a nenhuma faixa etária (MORAES et al., 2006).

Em nossa pesquisa, nenhuma das jovens entrevistadas apresentava ou relatou quadro emocional de maior gravidade. As inseguranças e ansiedades eram condizentes com as comuns às mães de primeira viagem. Não se sentiam deprimidas, extremamente ansiosas ou infelizes com a perspectiva ou o exercício da maternidade. Embora nem todas tivessem optado conscientemente por ter um filho nesse momento da vida, consideravam-se em condiçôes de cuidar do bebê. Além disso, a constituição de um novo núcleo familiar e a reordenação 
de laços já existentes em torno dos cuidados com o bebê proporcionavam uma vivência de amparo e segurança.

A história de Joana ilustra muito bem como um projeto de vida, que passa pela maternidade e pela constituição de um núcleo familiar, significou a possibilidade de projetar um futuro atraente, colaborando para a superação de um estado depressivo que se instalava.

Aos 17 anos, Joana é mãe de um menino de dois meses. Nascida no interior de Pernambuco, aos 11 anos veio morar no Rio de Janeiro com a mãe, cinco irmãos e o padrasto, que foi como um pai para ela. Os pais se separaram quando ela tinha três anos, e pouco depois ela se mudou com a mãe e duas irmãs mais velhas para Recife, o que a afastou do convívio paterno. A mãe se casou novamente e teve com o novo marido mais dois filhos. A família, assim reconfigurada, se transferiu para o Rio, e desde então moram todos juntos numa comunidade da Zona Norte carioca. O pai também constituiu outra família e ficou cada vez mais distante.

Joana conta que aos 14 anos teve um episódio de depressão disparado pela descoberta de que seu primeiro namorado, com quem já fazia projetos de casamento, a enganava. Ela comenta que a experiência, que desencadeou profunda tristeza, a fez lembrar do pai com quem praticamente não tinha mais contato.

Descobri que ele [o namorado] tinha uma filha, mas que nem era pai. Ser pai não é só dar dinheiro. Falo isso porque meu pai não teve presente na minha vida.

O término do namoro remeteu-a, portanto, a uma experiência precoce de perda que a marcou profundamente.

Ah, eu não gosto nem de lembrar, fiquei num desespero de ir para a rua e me jogar no carro. Fui até internada... Mas agora tudo bem, a minha vida mudou.

Esse episódio de depressão durou alguns meses e foi a partir do apoio que recebeu da família que começou a melhorar: "Eles queriam me fazer rir porque chorar, sofrimento, eu já tinha passado muito".

A família é muito presente em sua vida. Conversam, compartilham experiências, os maiores ajudam a cuidar dos menores, e o padrasto foi um ótimo pai. Joana conta que brigam e têm problemas como todas as famílias. A mãe é uma referência fundamental, a figura central e presença mais constante, pois o padrasto passa boa parte do tempo viajando por conta do trabalho. Cursa o ensino médio, porém não tem grandes expectativas em relação à escola. Acha que precisa do diploma para conseguir emprego. 

me formar para fazer uma coisa boa para o meu futuro... trabalhar de carteira assinada e dar uma vida confortável para ele [o filho], fazer que não falte nada dentro de casa.

Desde cedo ajuda em casa trabalhando como manicure. Quando teve oportunidade, gostou muito de frequentar algumas atividades promovidas por um projeto em sua comunidade. As atividades, no entanto, não duraram muito tempo. Diz que sempre quis casar e ter filhos, construir uma família.

Algum tempo depois de começar a reagir à sua depressão, conheceu José. Namoraram alguns meses e resolveram casar. Engravidou cerca de um ano depois do começo do namoro. Apesar dos temores e dúvidas iniciais, ficou feliz com a gravidez inesperada. A família, embora surpresa, recebeu bem a notícia e se dispôs a ajudar. Joana diz que agora está bem feliz, apesar de toda a trabalheira e o aumento das despesas. Sente-se valorizada e querida. Comenta que se tivesse o que tem hoje naquela época, não teria sofrido de depressão.

Joana parece mesmo estar bastante bem, feliz com o casamento, o filho e o apoio da família. No dia da entrevista, veio ao hospital com a irmã mais velha, que comentou, ao saber que Joana ia participar de uma pesquisa sobre gravidez na adolescência: "Dizem que isso é um problema, não? Mas no caso dela não foi problema, foi solução."

\section{As muitas faces da gravidez na adolescência}

A gravidez na adolescência é uma questão de muitas faces. É possível perceber a diversidade de situações nas quais um acontecimento dessa ordem pode se dar, com consequências também bastante diferentes. Somos confrontados com um panorama onde podemos destacar, entre outras, meninas que ao sofrerem abuso ou serem levadas a se prostituir muito precocemente, acabam por engravidar ${ }^{6}$ (GONTIJO; MEDEIROS, 2008; TRINDADE, 2005). Ou então jovens de camadas média e alta que, ao serem surpreendidas por uma gravidez inesperada, têm maiores condições e oportunidade de decidir levá-la ou não adiante (BRANDÃO, 2003). Ou jovens como as que participaram desta pesquisa, para quem a maternidade parece ser o projeto de vida mais palpável.

Abreu chama a atenção para o fato de que sobrevivem ainda hoje avaliações estreitas e preconceituosas sobre os valores e comportamentos amorosos das jovens dos setores populares. Avaliações que ganharam força desde o final do 
século XIX, quando médicos, juristas e membros do clero tinham um julgamento negativo sobre as moças pobres, negras ou brancas. Julgamento marcado por expressões como: meio viciado, devassidão de costumes, instintos perversos, falta de honra e educação. Ela lembra que qualquer análise sobre o comportamento dessas adolescentes deve buscar apreender a lógica e os significados desses valores e práticas dentro de um contexto social e histórico mais amplo (ABREU, 2004).

No entanto, os discursos médicos e psicológicos tendem a olhar a adolescente grávida através de um filtro reducionista e estigmatizante, denunciando essa herança. Assim, delineiam um perfil das jovens mães bastante desabonador para elas e suas famílias: seriam jovens com instrução precária, sexualmente desinformadas, inconsequentes, irresponsáveis, oriundas de famílias desestruturadas e vivendo em situação de marginalidade. A adolescente grávida emerge em toda essa produção discursiva situada numa posição limite, nas bordas da marginalidade e da fragilidade física e emocional.

As jovens entrevistadas não correspondem a esse estereótipo e insistem num projeto de maternidade, apesar de todas as dificuldades que enfrentam para concretizá-lo. Na contramão de uma biopolítica voltada para a regulação de sua fertilidade, exibem sua potência e capacidade de resistência.

Os programas de prevenção à gravidez na adolescência têm como foco privilegiado o controle da sexualidade da jovem, tanto em sua face pedagógica quanto sanitarista, por meio do incentivo ao uso de camisinhas e anticoncepcionais. Procura-se uma estratégia que possibilite um "exercício responsável da sexualidade”. Esses programas isolados, centrados apenas na regulação e adestramento da sexualidade, se não são acompanhados de projetos que possibilitem uma adolescência mais rica, criativa e prazerosa, acabam se tornando apenas mais uma restrição em suas vidas.

Para que a opção pela maternidade na adolescência não seja o único projeto de futuro atraente, é fundamental um olhar cuidadoso sobre as diferentes realidades nas quais as jovens mães estão inseridas, suas motivações e o lugar que a maternidade ocupa em sua economia psíquica. Uma diversidade que acaba obscurecida pela abordagem alarmista, universalista e homogeneizante que marca boa parte da produção discursiva em torno da gravidez na adolescência.

Esses discursos, e as políticas públicas deles derivadas, conceberam a maternidade na adolescência como risco social, enfatizando o aspecto 
irresponsável e inconsequente que a determinaria. Reforçaram, assim, a estigmatização dessas adolescentes, de sua sexualidade, de suas formas de vida. E ao pretenderem controlar uma fecundidade juvenil indesejada, confrontaram-se com as adolescentes grávidas e suas estratégias de resistência.

\section{Referências}

ABREU, M. Meninas perdidas. In: DEL PRIORE, M. História das crianças no Brasil. São Paulo: Contexto, 2004. p. 289-316.

ARIÈS, P. História social da criança e da família. Rio de Janeiro: Guanabara, 1978. 279 p.

BASSANEZI, C. Mulheres dos anos dourados. In: DEL PRIORE, M. História das mulheres no Brasil. São Paulo: Contexto, 1997. p. 607-639.

BAUMAN, Z. Vidas desperdiçadas. Rio de Janeiro: J. Zahar, 2005. 170 p.

BIRMAN, J. Gramáticas do erotismo. Rio de Janeiro: Civilização Brasileira, 2001. 253 p. Arquivo da biopolítica. In: Arquivos do mal-estar e da resistência. Rio de Janeiro: Civilização Brasileira, 2006. 418 p.

BRANDÃO, E.R. Individualização e vínculo familiar em camadas médias: um olhar através da gravidez na adolescência. Tese (Doutorado em Saúde Coletiva) - Instituto de Medicina Social, Universidade do Estado do Rio de Janeiro, Rio de Janeiro. 2003. 320 p.

BRANDÃO, E.; HEILBORN, M.L. Sexualidade e gravidez na adolescência entre jovens de camadas médias do Rio de Janeiro, Brasil. Cadernos de Saúde Pública, Rio de Janeiro, v. 22, n. 7, p. 1.421-1.430, 2006.

BRUNO, Z.V. et al. Maternidade e paternidade. In: COSTA, M.C.; SOUZA, R.P. Adolescência, aspectos clínicos e psicossociais. Porto Alegre: Artmed, 2002. p. 273-282.

CALligARIS, C. A adolescência. São Paulo: Publifolha, 2000. 81 p.

CASTRO, M.G. Controle da natalidade, legalização do aborto e feminismo. In:

Mulher hoje. Rio de Janeiro: Civilização Brasileira, 1980. p. 223-231.

COATES, V. História brasileira da medicina do adolescente. Adolescência latinoamericana. Porto Alegre, v.1, n.4, p. 260-265, 1999.

CORREA, M. Novas tecnologias reprodutivas: limites da biologia ou biologia sem limites? Rio de Janeiro: Eduerj, 2001. 263 p.

COSTA, F.C.C. A adolescência na medicina: um olhar antropológico. Tese (Doutorado em Antropologia). Programa de Pós-graduação em Antropologia, Universidade Federal Fluminense, Niterói, 2007. 197 p.

DADOORIAN, D. Pronta para voar, um novo olhar sobre a gravidez na adolescência. Rio de Janeiro: Rocco, 2000. 177 p. 
DEL PRIORE, M. História do amor no Brasil. São Paulo: Contexto, 2005. 330 p.

DONZELOT, J. A polícia das famílias. Rio de Janeiro: Graal. 1980. 209 p.

FACHEL, J.M.G.; LEAL, O.F. Jovens, sexualidade e estratégias matrimoniais. In: HEILBORN, M.L. (org.). Sexualidade, o olhar das ciências sociais. Rio de Janeiro: Jorge Zahar, 1999. p. 96-116.

FIGUEIREDO, B. Maternidade na adolescência: consequências e trajectórias desenvolvimentais. Análise psicológica. Lisboa, v. 18, n. 4, p. 385-498, 2000.

FOUCAULT, M. História da sexualidade I- a vontade de saber. Rio de Janeiro: Graal, 1977. 152p

. Les mailles du pouvoir. In: Dits et écrits, IV. Paris: Gallimard, 1994. p. 182-212.

FREIRE COSTA, J. Ordem médica e norma familiar. Rio de Janeiro: Graal, 1979. 282 p.

FREITAS, G.V.S. Comportamento suicida em adolescentes grávidas. Tese. (Doutorado em Ciências Médicas) - Faculdade de Ciências Médicas, Universidade Estadual de Campinas, 2007.

FREITAS, G.V.S.; BOTEGA, N.J. Gravidez na adolescência: prevalência de depressão, ansiedade e ideação suicida. Revista da Associação Médica Brasileira, São Paulo, v.48, n.3, p.245-249, 2002.

GONTIJO, D.T.; MEDEIROS, M. In: “Tava morta e revivi”: significado de maternidade para adolescentes com experiência de vida de rua. Cadernos de Saúde Pública, Rio de Janeiro, v. 24, n. 2, p. 469-472, fev. 2008.

HEILBORN, M.L. Experiência da sexualidade, reprodução e trajetórias biográficas juvenis. In: HEILBORN, M.L. et al. O aprendizado da sexualidade, reprodução e trajetórias sociais de jovens brasileiros. Rio de Janeiro: Garamond, 2006. p. 29-59.

MORAES, I.G.S. et al. Prevalência da depressão pós-parto e fatores associados. Revista de Saúde Pública, São Paulo, v.40, n.1, jan./fev. 2006. In: www.scielosp.org/scielo. php?script=sci_arttext\&pid=S0034-89102006000100011. Acesso em 23 set 2009.

NERI, M. Perfil das mães brasileiras. Rio de Janeiro. Fundação Getúlio Vargas, 2007. In: www.fgv.br/cps. Acesso em: 10 mar 2007.

. Motivos da evasão escolar. Rio de Janeiro: Fundação Getúlio Vargas, 2009. In: www.fgv.br/cps/tpemotivos/. Acesso em: 18 set 2009.

NUNES, S.A. Da medicina social à psicanálise. In: BIRMAN, J. Percursos na história da psicanálise. Rio de Janeiro: Taurus, 1988. p. 61-122.

. A medicina social e a questão feminina. Physis, revista de saúde coletiva, Rio de Janeiro, v.1, n.1, p.49-76, 1991.

- O corpo do diabo entre a cruz e a caldeirinha: um estudo sobre a mulher, o masoquismo e a feminilidade. Rio de Janeiro: Civilização Brasileira, 2000. 255 p.

PERROT, M. Figuras e papéis. In: História da vida privada: da Revolução Francesa à Primeira Guerra. São Paulo: Companhia das Letras, 1991. p.121-185. 

Minha história das mulheres. São Paulo: Contexto, 2007. 187 p.

ROUSSEAU, J.J. Emílio ou da educação. Rio de Janeiro: Bertrand Brasil, 1992. 581p.

SOBRINHO, C.L.M. et al. Aborto. In: COSTA, M.C.; SOUZA, R.P. Adolescência, aspectos clinicos e psicossociais. Porto Alegre: Artmed, 2002. p. 265-272.

TRINDADE, E. As meninas da esquina. São Paulo: Record. 2005. 412p.

VAN USSEL, J. Repressão sexual. Rio de Janeiro: Campos, 1980. 289 p.

\section{Notas}

${ }^{1}$ A esse respeito, ver: www.unesco.org.br/noticias/opinião/index/diadajuventude/mostra_documento. Acesso em 5/3/2007.

${ }^{2}$ Agradeço aos professores José Augusto da Silva Messias e Ana Maria Pinho, por terem acolhido essa pesquisa. Minha admiração e respeito pela dedicação e competência com que conduzem o trabalho docente e de assistência do Núcleo de Estudos da Saúde do Adolescente da UERJ.

${ }^{3}$ Os desejos femininos que extrapolassem o projeto materno, tais como aspirações profissionais ou artísticas, assim como comportamentos e formas de vida como adultério, prostituição ou homoerotismo, eram tratados como contra a natureza (NUNES, 1991).

${ }^{4}$ É interessante observar que esses aspectos passaram a fazer parte dos critérios relativos à idade adequada para procriar, que deixou de ser demarcada a partir de critérios fisiológicos. Até bem pouco tempo considerava-se que a idade ideal para procriar ia dos 18 aos 25 anos. A partir dessas transformações culturais e sociais essa faixa se alterou. Hoje se considera a faixa entre 20 e 29 anos como ideal. A esse respeito, ver: Machado, em: www.drauziovarella.com.br/entrevistas/gravidez35.asp. Acesso em 26/9/2009.

${ }^{5}$ É importante lembrar que naquela época considerava-se gravidez indesejada aquela ocorrida fora de um contrato conjugal, e não a gravidez durante a adolescência, até porque os casamentos nas camadas burguesas nessa faixa etária eram bastante comuns e mesmo arranjados pelas famílias. Segundo Priore, no Brasil a idade mínima para casar para as moças só passou de 12 para 14 em 1890, e para 16 em 1916 (Del Priore, 2005, p. 148). 


\section{Abstract}

Awaiting the future: teenage motherhood This paper is part of a research that aims to evaluate the place of motherhood in the constitution of subjectivity in a group of teenagers. It begins with the hypotheses that teenage pregnancy has become a political and social problem, inside a bio-politic targeting the production and reproduction of the social body. In this context, teenage pregnancy becomes a public health problem and the speeches about the subject tend to assume a homogenizing and stigmatizing tone, punctuating its negatives aspects. A research developed with teenagers from poor communities, between 16 and 18 years old, allows us to question these speeches. The research pointed out motherhood as a fundamental event in the constitution of these young women subjectivities. In fact, motherhood makes possible for them to built new ideals, and articulates a plan for the future.

Key words: teenage; pregnancy; bio-politics, forms of subjectivity. 